\title{
Cuerpos insumisos: Representaciones desde la disidencia sexual en la fotografía artística costarricense
}

\author{
Roberto Guerrero Miranda
}

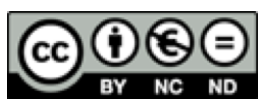

Esta obra está bajo una licencia Creative Commons

Reconocimiento-No comercial-Sin Obra Derivada 

Artículos

\title{
Cuerpos insumisos: Representaciones desde la disidencia sexual en la fotografía artística costarricense
}

\author{
Roberto Guerrero Miranda \\ Universidad de Costa Rica \\ robguerrero78@yahoo.com
}

Recibido: 16 de enero del 2016 Aprobado:18 de febrero de 2016

Resumen

El presente ensayo analiza la obra artística de cinco fotógrafos: Giorgio Timms, Jaime David Tischler, Sussy Vargas, Roberto Guerrero y Andrés Rangel, los cuales, aparecen como generadores, en diferentes generaciones, de representaciones artísticas fotográficas desde la noción de disidencia sexual. Dicho análisis tiene la finalidad de establecer una genealogía de los enfoques o acercamientos discursivos a las representaciones del cuerpo y del deseo no normativo, en la sociedad costarricense, en los años comprendidos entre 1989 y 2016.

La representación de los cuerpos desobedientes en la obra fotográfica de los artistas mencionados deriva en la compresión de cómo se ha mirado plural y ampliamente al cuerpo desde la fotografía de retrato y de desnudo, en un espacio temporal que abarca más de veinticinco años, y cómo esas formas de mirar pueden ser entendidas desde los campos epistémicos de la teoría queer, como armamentos contra la normatividad, archivos o documentos de resistencia y estrategias de intervención política en la colectividad. Se contrastan interpretaciones de la obra fotográfica de algunos de los artistas con informaciones provenientes de notas de prensa, con el propósito de relacionar los procesos creativos con el fenómeno de la recepción y establecer una correlación con el nivel cambiante de inteligibilidad social de los cuerpos y de las identidades.

Palabras clave: disidencia sexual, fotografía artística, fotografía costarricense.

\begin{abstract}
This paper analyzes the artistic work of five photographers: Giorgio Timms, Jaime David Tischler, Sussy Vargas, Roberto Guerrero and Andres Rangel as creators, in different generations, of photographic artistic representations from the notion of sexual dissidence, in order to establish a genealogy of
\end{abstract}




\section{Artículos}

approaches or discursive representations of body and a non normative desire in Costa Rican society, in the years between 1989 and 2016.

The representation of the disobedient bodies in the photographic work of artists mentioned leads to the understanding of how the body has been widely regarded from portrait and nude photography, in the temporary space of more than twenty five years, and how those ways of looking can be understood from the epistemic fields of queer theory as weapons against the regulations, files or documents of resistance and political intervention strategies in the community. Interpretations of the photographic work of some of the artists are contrasted with information from press notes, in order to relate the creative process with the phenomenon of reception and refer to a changing level of social intelligibility of bodies and identities.

Key words: sexual dissidence, artistic photography, costarrican photography. 


\section{Introducción}

Félix Guattari, en su artículo "Para acabar con la masacre del cuerpo" (1973), afirmó que "[...] lo inconfesable ha devenido, para nosotros, materia de reflexión, de difusión y de explosiones políticas, en el sentido en que la política manifiesta, dentro del campo social, las aspiraciones irreductibles de lo viviente" (párr. 21). En esas palabras, se convoca como un acto político, al imperativo de hablar y discutir sobre temas que la sociedad intenta negar, ocultar o ver de reojo. Eso que es "inconfesable" es la verdad del cuerpo, la de sus deseos o economía de placeres, la de su sexualidad y sobre todo, la de su visibilidad en el campo social. Para Guattari, en su crítica directa a un sistema social capitalista, patriarcal y represor del sujeto, la "consciencia revolucionaria" es una falacia si no pasa por el "cuerpo revolucionario"; es decir, aquel que gestiona "su propia liberación"1 (párr. 8).

Desde esa perspectiva, estrechamente relacionada con la conocida expresión feminista de Carol Harnish de que "lo personal es político" y con la enunciación artística de Barbara Kruger -del cuerpo como "campo de batalla" simbólico o potencia revolucionaria contra las represiones de un sistema dominante-, resulta pertinente exponer una serie de ideas sobre las relaciones entre la disidencia sexual, el cuerpo desobediente o insumiso y su representación, en una parte de la fotografía artística costarricense, producida desde la última década del siglo pasado, hasta la actualidad. Esto porque, en el presente, cabe la posibilidad de revisar los textos del pasado, de releerlos desde perspectivas de pensamiento distintas de aquellas en las que posiblemente fueron creados o al menos influidos; es factible y necesario analizar, contrastar y ampliar el alcance de las representaciones, al colocarlas un orden de discurso a tono con los procesos culturales que nos afectan hoy, donde se entiende que la visualidad y la estética constituyen un campo imbricado de discursos en constante negociación con lo social.

Desde esa premisa, resulta importante señalar las implicaciones políticas de la revisión de prácticas fotográficas producidas en Costa Rica desde finales de los años ochenta. A partir de estas, de manera clara, se puede establecer una genealogía de los enfoques o acercamientos discursivos a las representaciones de cuerpo, del deseo no normativo y del género; en fin, es factible visualizar la

${ }^{1}$ En relación con la idea de liberación, es importante tener en cuenta que aunque el texto Félix Guattari data de 1973 y que, desde ese tiempo y hasta la actualidad, se podría decir que se han dado algunos cambios significativos en cuanto a la idea de asimilación de identidades sexuales no normativas en algunas sociedades occidentales, es un hecho que los sistemas represivos continúan vigentes; lo anterior debido a que las instituciones sociales han buscado nuevas formas, no menos coercitivas, para ejercer su poder disciplinario en los cuerpos y para establecer y activar diferentes mecanismos de exclusión. La discriminación por sexualidad, género, clase social y etnia continua siendo una condición estructural e ineludible en las relaciones sociales e incide contundentemente en las condiciones reales de existencia de los sujetos. 


\section{Artículos}

operatividad problemática de la sexualidad, en una sociedad patriarcal conservadora.

En ese sentido, la representación de los cuerpos insumisos en la obra fotográfica de artistas de diferentes generaciones, tales como Giorgio Timms, Jaime David Tischler, Sussy Vargas, Roberto Guerrero ${ }^{2}$ y Andrés Rangel, deviene en la compresión de cómo se ha mirado plural y ampliamente al cuerpo desde la fotografía y desde subjetividades particulares, en un espacio temporal que abarca más de veinticinco años, y cómo esas formas de mirar pueden ser entendidas actualmente desde los campos epistémicos de la teoría queer, como armamentos contra la normatividad, archivos o documentos de resistencia y estrategias de intervención política en la colectividad, en tanto que emplazan lo íntimo e "inconfesable" - para algunos- o lo pulsionalmente incontenible -para otros-, en el espacio social costarricense.

Además, es importante resaltar que la comprensión actual, frente a las formas de mirar en años pasados, parece contrastar con los datos sobre la recepción que tuvieron las imágenes en el momento que se exhibieron, lo cual permite hacer referencia a un nivel cambiante de inteligibilidad social de los cuerpos y las identidades, que resulta necesario señalar en algunos casos particulares.

\section{La fotografía, el cuerpo y la disidencia}

Independientemente de su género de producción, de los niveles de artificio en su construcción o del grado de veracidad o valor testimonial que se le intente atribuir, se sabe que la fotografía es un medio que siempre tiene códigos que se conectan con algo de la realidad. Así que interesa, de forma particular, el hecho de que ese medio, en su potencia significante y acción interpretativa de lo real, es efectivo para revelar problemáticas más amplias sobre los sujetos y su entorno social, las cuales desbordan al registro informativo contenido en las imágenes y se imbrican discursivamente, al vincularse con las representaciones del cuerpo. $\mathrm{Al}$ respecto, David Pérez (2004) expone que

[...] cuerpo y fotografía en tanto procesos de construcción textual, constituyen

${ }^{2}$ Como autor de este artículo, pretendo exponer las inquietudes y motivaciones que me han llevado a producir obra artística fotográfica en el período comprendido entre el año 2000 y 2015 . Obra que revisa las representaciones de la masculinidad y la homosexualidad desde una perspectiva preeminentemente autorreferencial. El proceso de investigación documental que he realizado durante los últimos años, sobre los procesos sociales de construcción de las identidades de género, y de todo tipo de subjetividades, me ha llevado a interrelacionar mis procesos de realización artística con la revisión del trabajo de otras productores en el campo de las artes. En ese sentido, mi discurrir en este documento, se establece desde el espacio del desdoblamiento, el del artista que produce arte y, en medio de ese proceso, hace conjeturas sobre sus propios resultados y los de otros; siendo esto quizás, una debilidad o una fortaleza con respecto del analista que únicamente observa su objeto de investigación desde la distancia que ofrece la teoría y no desde la práctica. 
complejas elaboraciones discursivas que actúan no como meras presencias significantes despojadas de significaciones, sino como representaciones codificadas - a la par que codificadoras-dotadas de un plural carácter simbólico, económico, cultural, político, sexual, etc. (pp. 9-10)

De modo que el lazo fotografía-cuerpo, en tanto "construcción textual", puede funcionar inevitablemente como un mecanismo efectivo para la interpelación ideológica.

En ese sentido, la escritura de la imagen fotográfica, como acto de producción estética y técnica, es la captura o registro de la ideología -si se quisiera hacer una relación con el paradigma fotográfico analógico- o la reinvención o recodificación de las informaciones sobre lo ideológico, incidiendo en lo real -si se hace referencia a la tecnología digital. En todo caso, fotografiar lo que sea, y sobre todo al cuerpo, es la posibilidad de escribir, reinscribir o recodificar, en lo real, la conflictividad y las problemáticas del sujeto y su sociedad. Así, referir a la creación de la imagen fotográfica del cuerpo, puede constituir una metáfora para hablar de la creación del sujeto mismo, de sus condiciones de existencia y su devenir histórico.

En esa línea de pensamiento, fotografiar el cuerpo, en especial, aquel que ha sido objeto de proscripción y negación, constituye un acto revolucionario. La reinscripción en lo real, de la imagen del cuerpo -que a lo largo de la historia se ha construido como un objeto conquistable, colonizable, explotable, domesticable, producible y desechable, y que además es desobediente y objeto de invisibilización y exclusión- supone, haciendo referencia a Foucault (2008), contrariar deliberadamente al poder disciplinario de lo social y a sus mecanismos o dispositivos de funcionamiento. El emplazamiento visual y conceptual de lo negado se potencia a sí mismo desde su capacidad de trastorno de las lógicas de orden y de normalización de lo colectivo. Es así que la fotografía activa su capacidad de recodificar la operatividad de su lenguaje formal y significante, y participa en los procesos ideológicos de la disidencia; mediante la acción discursiva ${ }^{3}$

\footnotetext{
${ }^{3}$ Aquí es importante resaltar que la acción discursiva de la fotografía, se complejiza, en la medida en que la capacidad significante del medio fotográfico se amplifica al estar anudada con la dimensión técnica de captura y reproducción de imágenes y con la dimensión formal, matérica y estética que determina su visualidad. Esta unión borromea de las dimensiones de técnica, forma y contenido ha problematizado a los estudios de la historia de la fotografía y, a su vez, en el caso de Costa Rica, ha determinado una comunicación a medias con la historia del arte, debido a que esta última parece centrarse principalmente en el análisis de los usos discursivos de la fotografía por parte de los artistas, y no aplica enfoques analíticos que integren dialécticamente a la técnica y forma fotográficas. Es un hecho que el estudio específico de la historia o de filosofía de la fotografía requiere de la construcción de marcos teóricos específicos para el medio, que a menudo coinciden con los del arte, pero que, en esencia, son diferentes, los cuales -me aventuro a afirmar- no se estudian de manera específica en las carreras de Historia del Arte del país.
} 


\section{Artículos}

de la noción de verosimilitud, la capacidad testimonial y narrativa, el efecto de realidad o de ficción deliberada y, sobre todo, por medio de la potenciación de géneros de representación fotográfica, como el retrato y el desnudo. ${ }^{4}$

\section{Genealogía de cuerpos insumisos en la fotografía costarricense}

Los géneros del retrato y/o el desnudo se presentan como un eje para enlazar las producciones fotográficas comprendidas entre el final de la década de los ochentas del siglo XX y la actualidad. El trabajo producido por los artistas Giorgio Timms, Jaime David Tischler, Sussy Vargas, Roberto Guerrero y Andrés Rangel resulta significativo de revisar, porque evidencia distintas manifestaciones de representaciones de la disidencia sexual en el ámbito artístico costarricense, cruzadas, a su vez, por diferencias generacionales que permiten pensar en el cambio de mentalidades sobre la visión del cuerpo y su discursividad en el ámbito social.

La imágenes de Giorgio Timms (n.1947) constituyen las primeras representaciones fotográficas del desnudo masculino que, en Costa Rica, se expusieron al público, en un contexto artístico, alrededor de 1989. Las

\section{Figura 1}

Giorgio Timms, Sin título, serie: Proyecto Efe, Fotografía en color solarizada (1989)

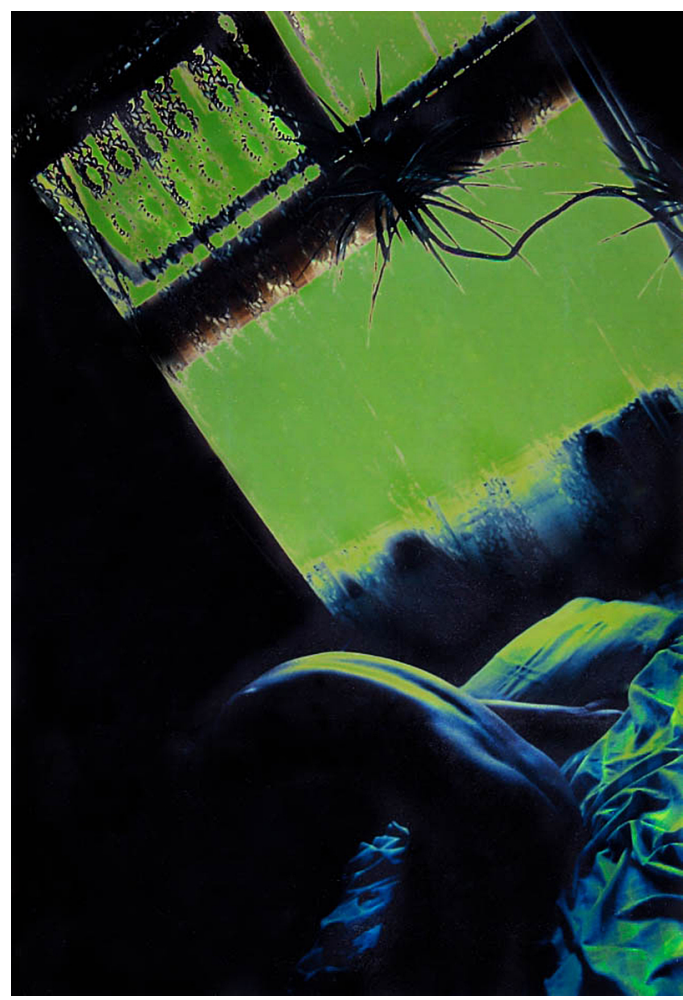

Fuente: Giorgio Timms

primeras imágenes de lo que sería la serie fotográfica titulada Proyecto efe, se empezaron a gestar en los últimos años de los ochenta, como un ejercicio académico de fotografías solarizadas para ilustrar, con una imagen de

\footnotetext{
${ }^{4}$ Las representaciones del retrato, son entendidas aquí como la materialización de una mirada discursiva a la identidad personal y la colectiva, y las del desnudo son concebidas como contenedoras potentemente significantes para esas identidades; se imbrican en la fotografía del cuerpo y en el caso de aquél que es desobediente, ponen en un orden de discurso, recordando a Kristeva (1993), a posibles enfermedades del alma - producidas desde un entorno externos y ajeno al sujeto, es decir el campo social-, ante las cuales surge la necesidad de rebelión y de búsqueda de la libertad.
} 
desnudo masculino, la portada de un poemario de la escritora costarricense Ana Istarú.

Cabe destacar que el mencionado libro, el cual motivó la realización de las fotografías de Timms, se integraba de poesías eróticas de una mujer hacia un hombre y que, significativa y contradictoriamente, ya estaba ilustrado por una imagen pictórica de un desnudo femenino. Timms realizó varias fotografías para la publicación del libro, de las cuales, cinco fueron expuestas después en el Salón Nacional de Fotografía de 1989, que convocaba el Museo Arte Costarricense y, en el cual, obtuvieron la distinción de mención de honor y el premio del primer lugar del público que se otorgaba por la votación de los visitantes de la exposición. Posteriormente, también fueron exhibidas en la muestra colectiva Propuestas 89 , organizada por la misma institución. ${ }^{5} \mathrm{Al}$ siguiente año, en 1990, la serie se completó y se expuso, en una muestra individual en la Galería del
Teatro Nacional, lugar donde, por primera vez, se mostraba fotografía y, además, de desnudo masculino.

Aunque para 1990, y en los cinco años siguientes, a nivel mundial, hubo un interés nunca antes visto sobre estudios de género y de masculinidades -así como un resurgimiento del desnudo masculino en la fotografía ${ }^{6}$ - de los datos históricos anteriores, es relevante el hecho de que el trabajo de Giorgio Timms constituyó el primer emplazamiento del desnudo masculino en el ámbito artístico costarricense y, sobre todo, resulta esencial que se dio la presentación de la temática del deseo homoerótico en y desde la fotografía, al público de la época.

Lo anterior, marcó una ruptura que interesa tomar como punto de partida para esta genealogía de cuerpos insumisos, porque simboliza la irrupción del deseo que se tradujo como una mirada pulsional al cuerpo.

\footnotetext{
${ }^{5}$ El Museo de Arte Costarricense, ese mismo año de 1989, en conmemoración de los 150 años de la invención de la fotografía, le pide a Giorgio Timms que represente, junto con el trabajo de Victoria Cabezas, a Costa Rica en una exposición internacional organizada por el Museo de Arte Latinoamericano en Washington, que se conformaba del producciones fotográficas de creadores de las naciones integrantes de la OEA. Para ese momento, Giorgio Timms se había abocado a la realización de fotografías de desnudo masculino, muchos de los cuales no se conocieron en Costa Rica, que se expusieron también en Puerto Rico, Nueva York y París (Timms, 2016).

${ }^{6}$ Teniendo como gran antecedente las olas de la teoría feminista, a Foucault, a un construccionismo social, el primer lustro de los noventas trajo una extensa revisión crítica de las masculinidades y sobre todo, un desplazamiento hacia el estudio del sexo y de la sexualidad. Por ejemplo, recordemos que en 1990 se publicó El género en disputa de Judith Butler y Epistemología del Armario de Eve Kosofsky, Butler en el 1993 publicó Los cuerpos que importan: Sobre los limites discursivos del sexo; en 1995, R. W Connell publicó Masculinidades y David Halperin publicó San Foucault: hacia una hagiografía gay, y alrededor de 1996, Leo Bersani publicó su libro Homos.
} 


\section{Artículos}

Figura 2

Giorgio Timms, Sin título, serie: Proyecto Efe, Fotografía en color solarizada (1989)
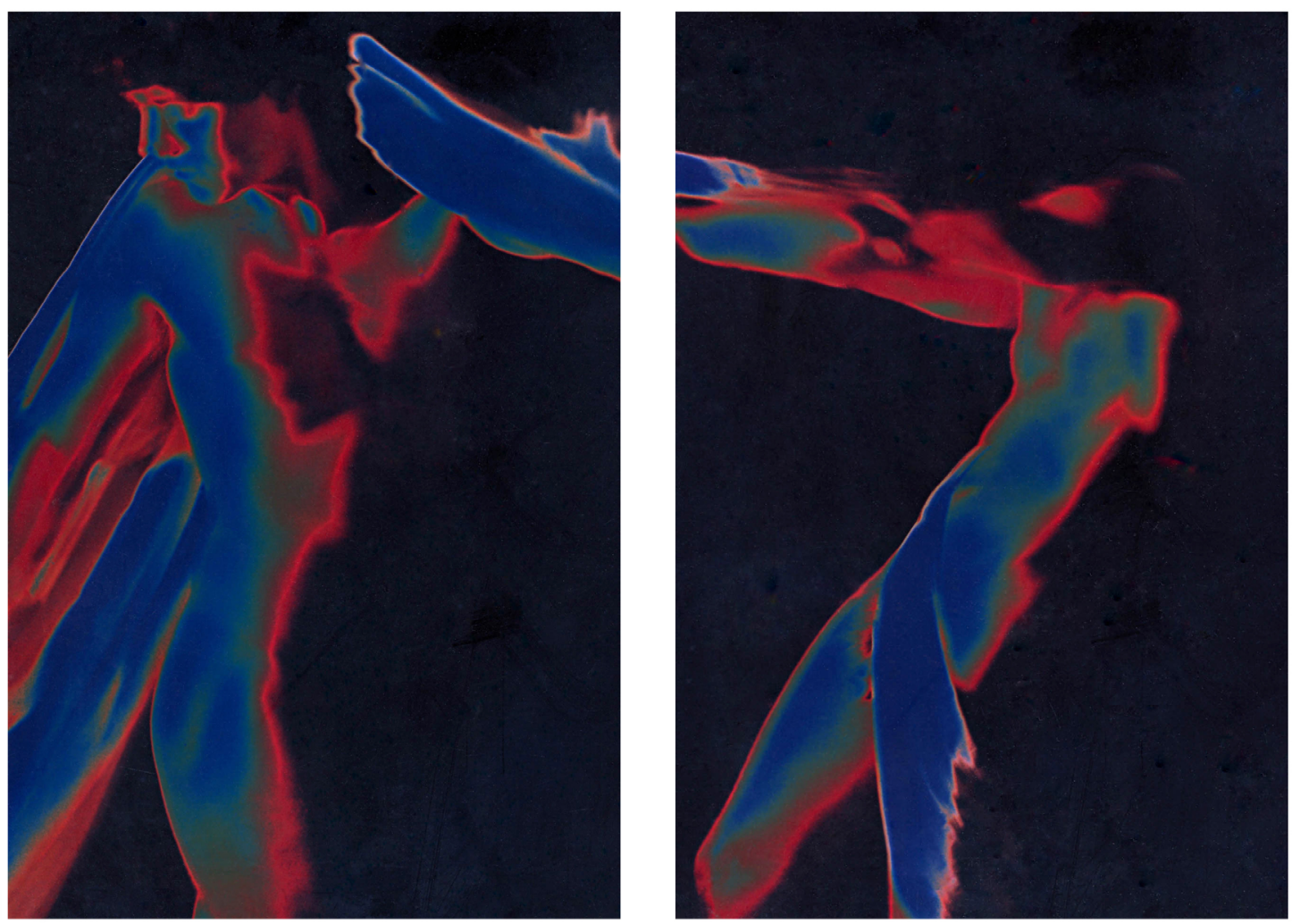

Fuente: Giorgio Timms

Siguiendo a Juan David Nasio (2001), la mi-

Considerado desde la perspectiva actual, el rada de Timms se equipara a la satisfacción erótica, ya que es una mirada “ [...] que aparece, sea como acto, sea como movimiento, es una acción -la mirada agarra- [a los cuerpos masculinos fotografiados] o bien es la satisfacción de ese acto" (p.24), que en términos lacanianos, se denomina "goce". acto de permitirse ese goce, primero como una experiencia íntima de creación artística y luego como un acto deliberado de intervención política al exhibirlo públicamente, puede interpretarse como un primer y relevante acto de transgresión y desobediencia de la norma heteronormativa. 
En contraste con lo mencionado, es fundamental resaltar la importancia que tiene la técnica de la solarización en color que Timms efectuó en sus fotografías de desnudo, ya que si se revisan las publicaciones de crítica de arte de la época, relacionadas con las fotografías expuestas en el Salón Nacional, se impone un análisis técnico formal de las obras y no de su contenido. Por ejemplo, en el artículo del periódico La Nación "Salones Nacionales'89: Y venció el arte” (7 de enero, 1990), se señala:

En fotografía topamos con la confrontación habitual entre blanco y negro y color, por una parte, y entre los méritos de la intervención química y la pureza del que se limita a la composición en el visor [...]. El idioma fotográfico tiene sus propios códigos muy diferentes y prácticamente incomparables en el blanco y negro (contraste como valor) o color (cromatismo como gramática). Por ello el jurado otra vez escogió la tibieza de la concesión y mencionó dos tendencias dispares: un excelente desnudo solarizado en color de Giorgio Timms y el melifluo «Matute» en blanco y negro de Teresita Chavarría. (pp. $2 \mathrm{D}$ y 3D, Suplemento Áncora)

El texto anterior permite formular la hipótesis de que la verbalización explícita del tema de un deseo homoerótico, en el arte fotográfico, quedaba fuera de la inteligibilidad de la crítica y de los medios de comunicación de la época, los cuales se limitaron únicamente hablar de forma y de recursos técnicos. Eso contrasta contundentemente con lo que escribió el propio autor en el brochure de la exposición Propuestas 89, acerca de las mismas imágenes que estuvieron en el Salón Nacional de Fotografía:

El disfrute pleno, la libertad, el juego físico e intelectual, la autenticidad y el amor; son éstos los sentimientos con los que enfrento el acto fotográfico y sin los cuales no podría -o al menos no querría- realizarlo.

Las fotografías que presento, son las primeras imágenes resultantes de una investigación técnico-temática, que reúne el desnudo masculino y la solarización en color; como tales conforman tan solo el inicio de un trabajo en proceso, cuyo perfil no se definirá sino hasta el momento en que el círculo se cierre y pueda afirmar que esta pasión ha llegado a su fin. (Timms, 1989)

La implicación personal e íntima con la que se asume el propio trabajo artístico de dicho autor, queda claro en el texto anterior, de forma específica, en relación con el goce y la inscripción y enunciación pudorosa del deseo homoerótico como generador de una práctica estética, que, en la actualidad, se puede interpretar como una acción ética de lo disidente, en materia de sexualidad. Timms estaba ya consciente, en 1989, de su búsqueda conceptual y carnal, y del uso que le daría a los recursos técnicos en la toda la fotografía de desnudo masculino que produjo en años posteriores; sin embargo, en la recepción oficial de las imágenes se elude el tema de fondo y la apreciación y la puesta en discurso de la obra se reduce sólo 


\section{Artículos}

al comentario sobre lo técnico-formal. Ese acto de negación pone de manifiesto el fuerte orden regulatorio de la cultura de la Costa Rica de finales de los ochenta y principios de los noventa, que deviene en la imposibilidad de hablar sobre una realidad concreta: la del deseo homosexual.

Durante el segundo lustro de la década de los noventa, Jaime David Tischler (n.1960) regresa a Costa Rica luego de vivir en Europa y de estudiar fotografía en ese lugar. A principios de 1997, realiza la exposición fotográfica Sendas Equívocas en la Galería Nacional de Arte Contemporáneo, perteneciente al Museo de Arte Costarricense. La exposición se integró de series fotográficas: Azar y otros eclipses, Bajar al cielo, Fragmentos de un mendicante y Pies de barro, realizadas entre 1994 y 1996, de forma aproximada.

En muchas de las fotografías de Tischler se evidencia la representación del cuerpo masculino, del deseo y el encuentro homosexual, de manera obvia. A diferencia de las fotografías de Giorgio Timms, donde el acto de la mirada es contemplativa de un cuerpo solitario, en muchas de las representaciones de Tischler, se hace patente la mirada enfocada a un anudado de varios cuerpos en acción sexual, en las que él mismo, a veces ha participado.

Además, la inclusión de autorretratos en sus series fotográficas denotan la intensa implicación personal en la representación fotográfica, marcando de este modo, otro momento muy distinto en la genealogía de los cuerpos insumisos: se observa un emplazamiento

\section{Figura 3}

Jaime Davis Tischler, El equilibrio precario de tu deseo, Serie: Pies de barro, Fotografías gelatina de plata (1996)

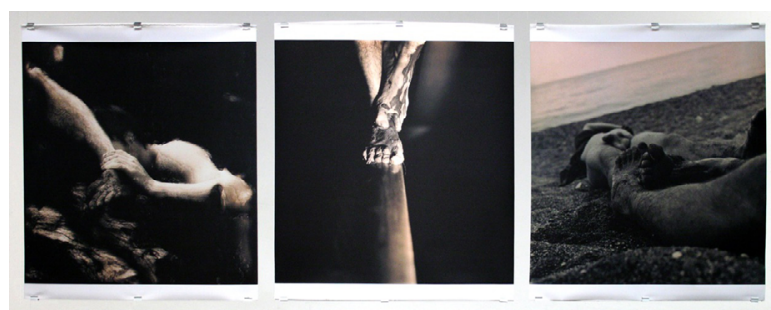

Fuente: Museo de Arte y Diseño Contemporáneo

de la homosexualidad en la fotografía en Costa Rica, desde la autorrepresentación y de la afirmación de su propia identidad de Tischler como homosexual.

Sin embargo, resulta importante mencionar que al mismo tiempo que la representación hacía evidente el tema del deseo y el encuentro homosexual, las técnicas de captura de la imagen analógica, los procedimientos de revelado de la película y de impresión, funcionaron como un velo que permitía observar los cuerpos detrás de una serie de recursos visuales poéticos. El efecto de la conjunción de técnica y forma fotográficas que Tischler le dio a muchas de sus fotografías no distaba mucho del solarizado que Giorgio Timms aplicó a sus primeros desnudos masculinos.

En el suplemento "Áncora" del periódico $L a$ Nación, del 30 de marzo de 1997, el artista José Miguel Rojas aduce que Tischler intenta: "[...] explicar de manera metafórica el mágico proceso fotográfico $-\mathrm{o}$ la alquimia 
fotográfica dentro del laboratorio-, ya que de alguna manera, un fotógrafo tiene algo de demiurgo y algo de cíclope que busca sus propias sombras en esa fábula que es la realidad" (párr. 3). Esto recuerda, en cierto modo, las apreciaciones técnico-formales que años antes se habían hecho de la obra de Timms, para eludir directamente a su contenido. En ese contexto, el silencio -o verbalizar a medias- seguía siendo una manifestación de la imposibilidad de emitir criterios, en público, sobre la diferencia sexual.

Cuando Jaime Tischler mostró las imágenes de la serie Fragmentos de un deseo mendicante, ese mismo año, en la Biblioteca José Figueres Ferrer del Instituto Tecnológico de Cartago, las imágenes fueron bajadas del recinto de exposición y se generó una reacción violenta por parte de los estudiantes de esa institución académica. Ese acto realmente significativo puso en evidencia la incapacidad de un sector de la sociedad costarricense de enfrentarse a la representación del deseo y del cuerpo no normativo. Con respecto a ese hecho, el 20 de febrero del año 2000, en el suplemento "Áncora" del periódico $L a$ Nación, Julia Ardón escribió:

Una de sus exposiciones, hace poco, fue tirada literalmente al piso en el Instituto Tecnológico en Cartago, aduciéndose que era una "cochinada». Incluso gente cercana, y de buena fe, en algún momento le pidió cambiar de tema para no encasillarse y no cerrarse las puertas de museos donde asisten niños. (párr. 10)

El texto anterior, el cual se extrae de una entrevista que se le hizo al artista, pone de manifiesto la consternación de los espectadores al enfrentarse a la obra fotográfica de Tischler y, sobre todo, el mecanismo de defensa social: la recurrencia histórica a categorías de exclusión de lo que no se apega a la norma, tal como la higiene y salud pública, y la salvaguarda de la niñez, evitando su contacto con lo que socialmente se considera perverso. El propio autor, sobre el mismo hecho, años después, en el 2005, en la entrevista "Domingo Siete: Jaime Tischler. En la piscina honda", publicada también en el suplemento "Áncora" del periódico La Nación, expresó:

[...] lo que me preocupaba no era el daño material, sino la cólera, esa ira popular de los demás, que me despertó quién sabe qué genes ancestrales ante ese odio. Era como si te dijeran: -sos diferente, cómo te atrevés a desplegar tu diferencia, tu «deformación», frente a nosotros-. Yo venía de Europa, muy «fresa», creyendo que aquí era como allá, y cobré conciencia de que esto es lo que tengo y lo que escogí. Claro que en este episodio está el otro lado: el de mi fascinación por el proceso, por el acto social que implica la fotografía, la interacción con la gente. Yo sabía que iban a murmurar, pero no esperaba esta conmoción, el odio y la discriminación, que se sintieran amenazados por esas imágenes. (párr. 16)

En este recuento de los cuerpos insumisos, de forma precisa, interesa resaltar la amenaza a las estructuras normativas que las fotografías de Jaime Tischler representaron para 


\section{Artículos}

la sociedad costarricense de 1997; la presencia de lo disidente no era resistida por el entorno, lo que devino en violencia. El trabajo del artista significó una representación de ese "cuerpo revolucionario" del que habla Guattari que, en la fotografía, ha reclamado su espacio de liberación de los ideales regulatorios de una cultura heteropatriarcal y que se ha afincado en lo real, al afirmar la existencia y permanencia de una identidad sexual que se entiende a sí misma como desobediente.

En un estrecho dialógo temático y temporal con los trabajos de Giorgio Timms y de Jaime Tischler, se encuentra la obra artística fotográfica de Sussy Vargas (n. 1967), quien expone, en el contexto costarricense, una perspectiva femenina de la disidencia sexual. El trabajo de Vargas ha integrado el desnudo con fuertes referencias a la iconografía religiosa. Al respecto, Ileana Alvarado y Efraín Hernández (2004) señalan que la artista "[...] trabaja con imágenes de cuerpos dolientes, atormentados quizá por las dicotomías que se tensan entre el deseo y los discursos religiosos acerca del cuerpo y la consecución del deseo" (p.94). Sin embargo, esa descripción no es tan abarcadora para lo que interesa en este artículo, ya que desde principios de la década del 2000, con el ensayo fotográfico Las formas del silencio, Sussy Vargas, por medio de la fotografía, ya trataba el tema de su identidad lésbica y empieza una serie de búsquedas creativas y discursivas que emplazan contundentemente al cuerpo y al deseo de la mujer, desde una política de autoreivindicación.
Claudia Mandel Katz (s.f.) en su ponencia "Cuerpos disidentes en América Latina", cita a la artista, quien explica que su serie Las formas del silencio, buscaba

[...] reflejar toda la frustración e incomodidad que durante toda mi vida he sentido al tener que sobrevivir en medio de la doctrina social del silencio impuesto por la sociedad ante mi condición de mujer en primer lugar y luego ante mi sexualidad lésbica. Estos temas los abordé desde 1996 de una manera más sutil hasta la actualidad a partir de propuestas más directas y menos complacientes, como el caso de mi última serie; «Poemas cotidianos» (2013-2014), donde enfrento a los espectadores a entrar en mi espacio más íntimo y privado. (Vargas, 2014, citada por Mandel Katz, párr. 4)

Interesa comentar la serie Poemas Cotidianos, en la cual artista se autorretrata desnuda con su pareja en espacios privados: su habitación, su taller de artista y diferentes cuartos de hotel. Estas fotografías confrontan al espectador con el encuentro íntimo de dos amantes. El amor lésbico como eje de una identidad disidente se hace evidente y reclama visibilidad $y$, principalmente, naturalidad. Ese reclamo constituye, desde los instrumentos discursivos que ofrecen la fotografía y el arte, un acto de intervención política en el régimen patriarcal y heteronormativo, el cual siempre busca negar u ocultar a la disidencia. En este contexto, resuenan con gran vigencia las palabras de Guattari, quien expresó que: 


\section{Figura 4}

Sussy Vargas, Sin Título, Serie: Poemas Cotidianos, Fotografía digital (2014).

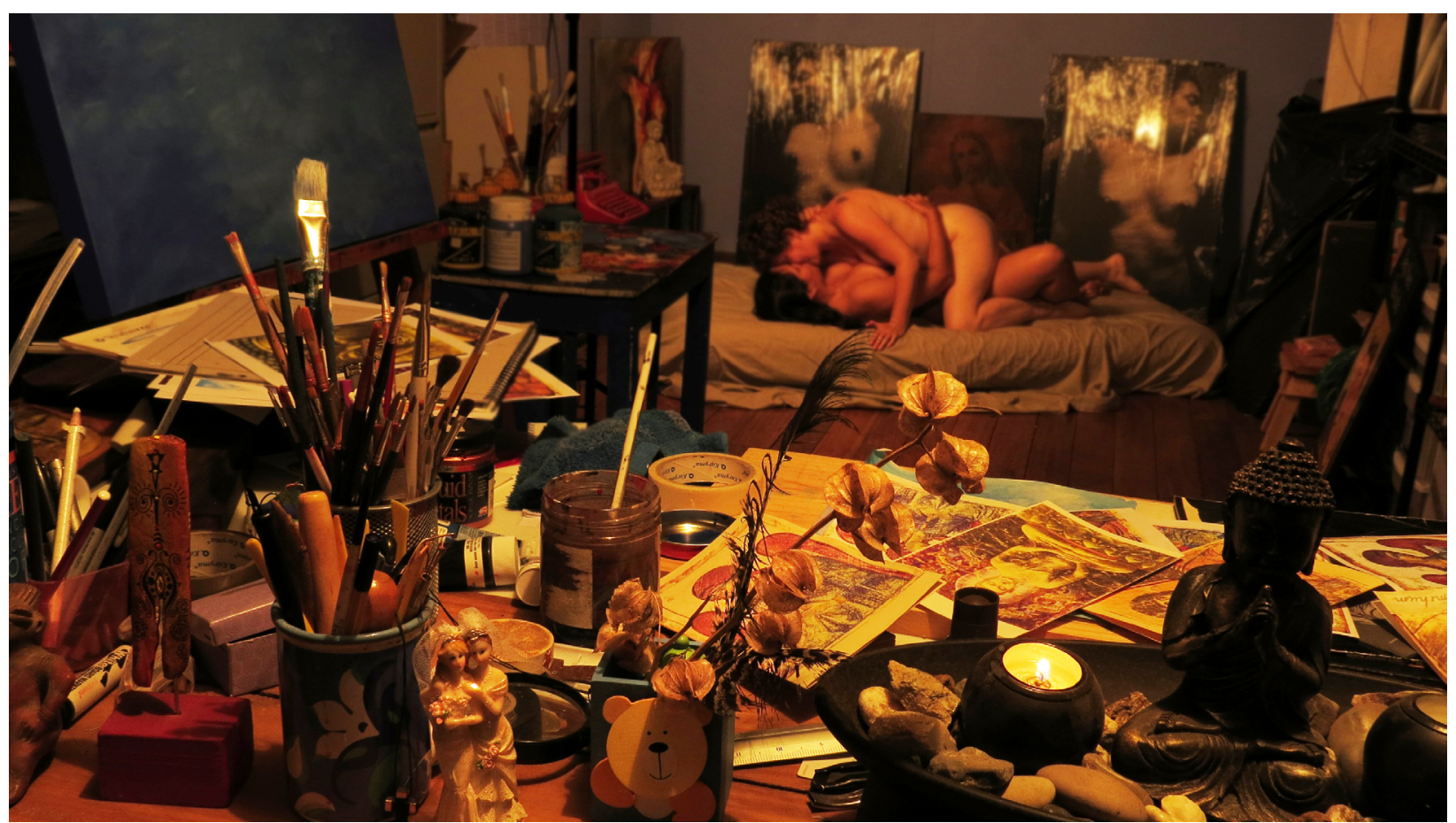

Fuente: Sussy Vargas

Son las mujeres en rebelión contra el poder masculino -implantado desde hace siglos en sus propios cuerpos-, los homosexuales en rebelión contra la normalidad terrorista, los «jóvenes» en rebelión contra la autoridad patológica de los adultos, quienes han comenzado a abrir colectivamente el espacio del cuerpo a la subversión, y el espacio de la subversión a las exigencias inmediatas del cuerpo. (párr. 9)

La capacidad subversiva de la obra de Sussy Vargas además se potencia, en la medida en que ella renuncia a la implementación de recursos formales y técnicos de la fotografía ${ }^{7}$,

\footnotetext{
${ }^{7}$ La obra anterior de Sussy Vargas, aquella producida en la década de los noventa y la primera parte de la del 2000, sí tiene una recurrencia en el uso de recursos formalistas en la fotografía, principalmente provenientes de la manipulación de la imagen en el laboratorio químico y la intervención posterior de las impresiones con materiales pictóricos y alternativos. Estos recursos deberían ser analizados de manera conjunta a los contenidos de sus obras.
} 
Artículos

Figura 5

Sussy Vargas, Sin Título, Serie: Poemas Cotidianos, Fotografía digital (2014).

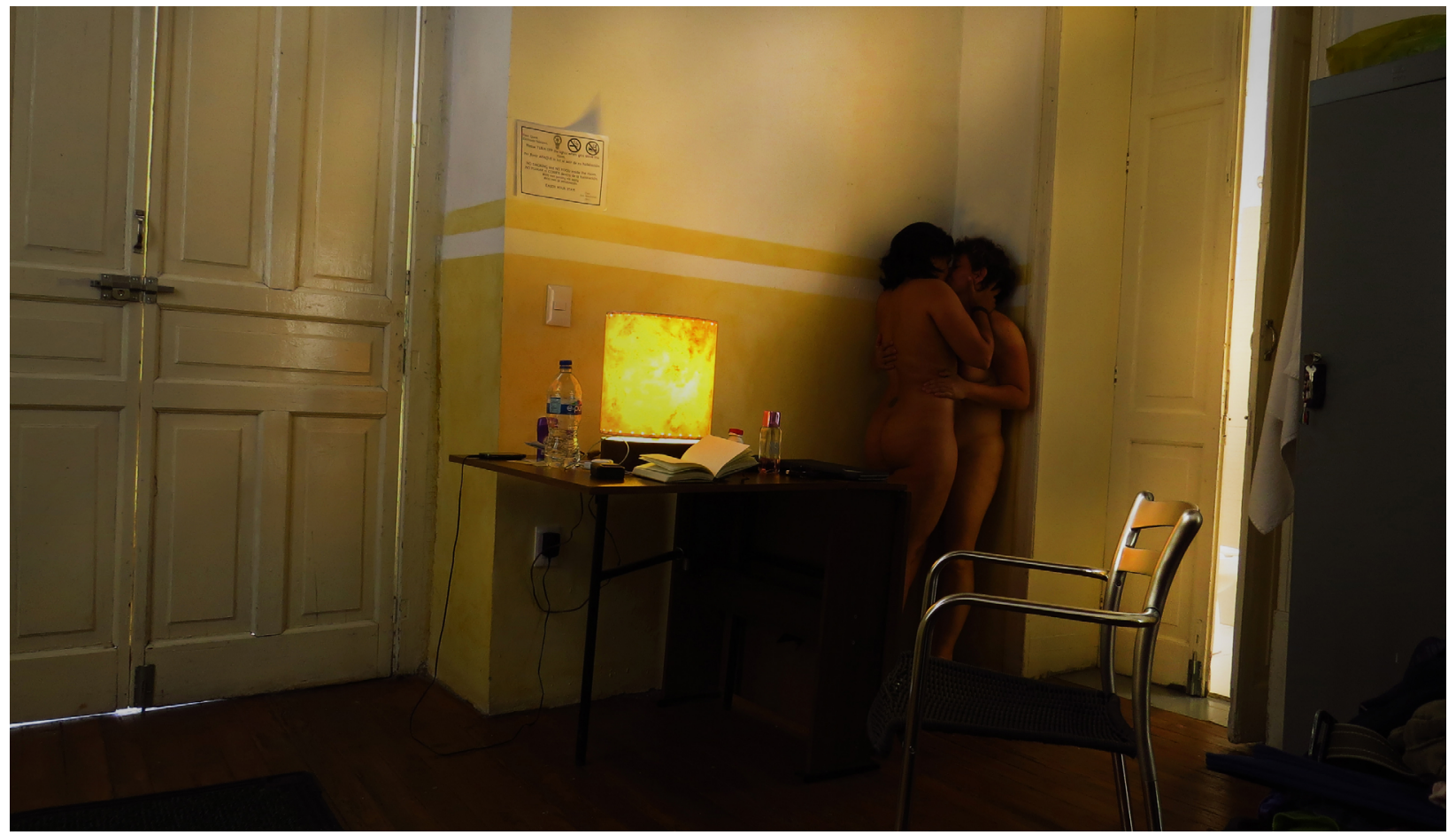

Fuente: Sussy Vargas

en Poemas Cotidianos. A diferencia de obras fotográficas de momentos anteriores, las fotografías de esta serie, presentan una especie de documentación cruda de la realidad íntima de la artista, que parece convocar a elementos estéticos del realismo. Además, permiten conectar la obra reciente de Vargas con el trabajo de la fotógrafa Nan Goldin, el cual se caracterizó por el registro fotográfico de lo cotidiano, liberado del preciosismo formalista fotográfico y cuyo contenido se centra en documentar -de forma autorreferencial- su mundo íntimo, sus amigos y amantes; todo con una gran carga pulsional.
La publicación de la serie Poemas Cotidianos se realizó, en 2014, en el sitio www.museodelasmujeres.co.cr, el cual está disponible actualmente en Internet. No obstante, es importante resaltar que 13 de julio de 2014, el suplemento "Áncora" publicó una breve reseña informativa sobre la muestra, en la que se comunica:

Las 25 fotografías que presenta Sussy Vargas recuerdan la constante represión que ha sufrido una generación entera en cuanto a su preferencia sexual. La preocupación de la artista por las luchas sobre los derechos de las comunidades gay, 


\section{Figura 6}

Sussy Vargas, Sin Título, Serie: Poemas Cotidianos, Fotografía digital (2014).

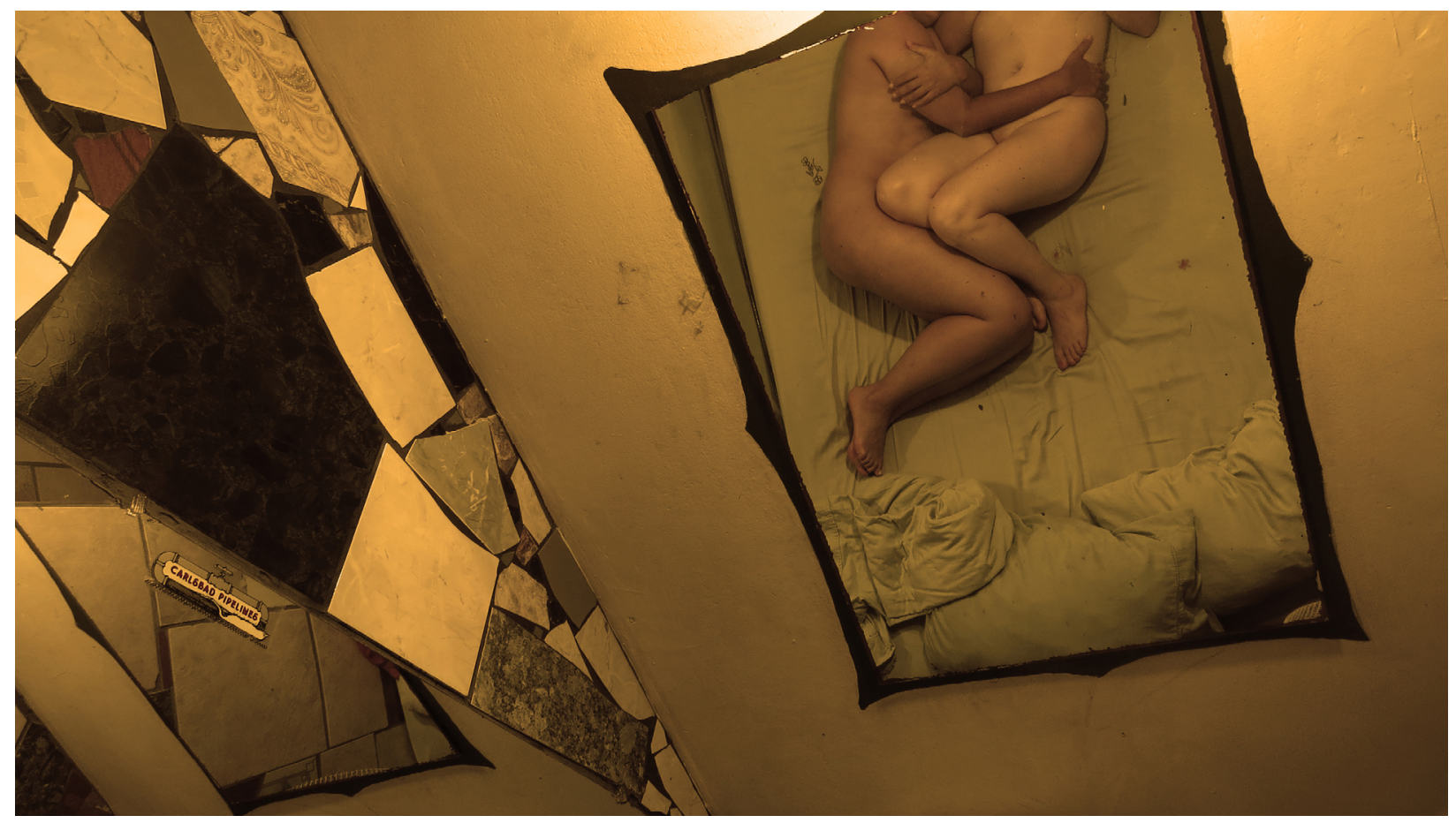

Fuente: Sussy Vargas

lésbico y transgénero hacen que ella se enfrente contra la ignorancia, los tabúes y los miedos que se crean alrededor de las parejas homosexuales.

Las obras realizadas entre el 2013 y la actualidad, son celebraciones de la vida cotidiana en pareja. Sussy Vargas busca «evidenciar que finalmente no somos diferentes de otras parejas que en su día a día sueñan, se abrazan, se aman con ternura o furia, crecen, se desgastan la piel a puros besos, viven y se reconocen como parte de una familia, de un lugar, de un espacio y de un momento».
Las imágenes de este ensayo visual hablan del mundo de lo íntimo y lo sagrado, espacios conquistados por la absoluta desnudez de quien no oculta o pretende ocultar. (recuperado en línea)

Esta publicación permite acercarse al pensamiento de la artista sobre el imperativo de validar públicamente la economía de sus afectos y placeres, de emplazar su cuerpo y su deseo, de una forma natural en lo real. Además, el texto posibilita observar un enfoque distinto y sobre todo, explícito en la comunicación de contenidos sobre el tema 
Figura 7

Sin título (2015)

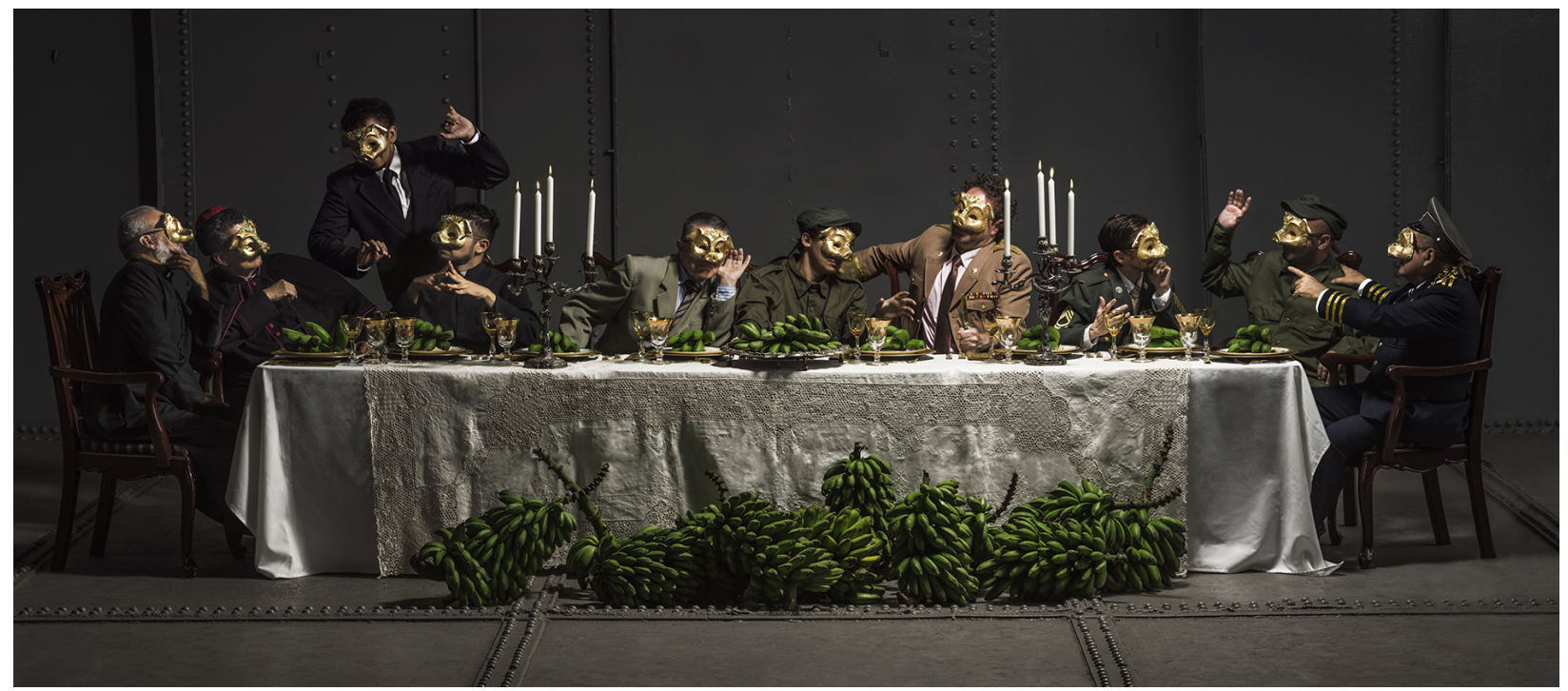

Fuente: Roberto Guerrero

diferencia sexual, que contrasta con las informaciones publicadas sobre el trabajo de Timms y de Tischler, durante los años noventa. La nota hace referencia a la discriminación social sufrida por los sujetos y a la respuesta reivindicativa que hace la artista con su obra fotográfica y, de manera enfática, a la intención de no ocultar la realidad de su sexualidad. A partir de esto, se podría afirmar que existe un cambio en el nivel de inteligibilidad los cuerpos y las identidades disidentes, como resultado de su constante demanda de visibilidad y reconocimiento en todos los ámbitos del entorno social.

El reclamo de visibilidad de una identidad disidente es lo que ha caracterizado la obra fotográfica de Roberto Guerrero (n. 1978), quien desde el año 2000 -y coincidentemente, influenciado por la obra Jaime Tischler-, comenzó a hacer autorretratos que incorporaban elementos de la identidad femenina junto a su cuerpo masculino desnudo. Alrededor del año 2003, estas búsquedas se alternaron con representaciones fotográficas fantásticas, cargadas de simbolismos sobre el purgatorio, el infierno y la pasión, producidas con materiales analógicos, mediante la aplicación creativa de técnicas de iluminación y fotomontaje.

A partir del 2004, el artista dejó de lado los efectismos técnicos y formales propios de la fotografía y empezó a desarrollar imágenes que integraron elementos del diseño gráfico y un manejo de las posibilidades discursivas de 
la relación entre imágenes y textos. Esto dio como resultado una serie de autorretratos, en los que el artista se presenta como un personaje que parodia los estereotipos de masculinidad propios de revistas de circulación masiva, tales como Men's Health y Popular Mechanics.

En estos proyectos, se impuso un uso conceptual y discursivo de la fotografía para emplazar, en el imaginario colectivo, a un sujeto disidente, que asume en su propio cuerpo, la coexistencia de lo femenino junto a lo masculino. Incluso, la preeminencia del contenido sobre la forma, llevó al artista a desplazarse de un uso bidimensional de fotografía hacia una hibridación con la tridimensionalidad, la imagen en movimiento y los objetos; todo esto con la finalidad de representar a un sujeto disidente que se reconoce en su diferencia y que, de forma distinta a generaciones anteriores, la utiliza deliberadamente para desestabilizar a las estructuras del poder heteronormativo. En esa línea de pensamiento, en la ponencia "Repensando la Vergüenza", dictada en el Museo de Arte y Diseño Contemporáneo [MADC], en setiembre de 2015, Guerrero afirmó:

Es una verdad de Perogrullo, que la feminidad en la masculinidad es una condición inaceptable dentro de las estructuras de poder que predeterminan a los sujetos en una sociedad patriarcal. Asimismo, lo es el hecho de que el deseo homosexual históricamente, haya sido entendido como un pecado, enfermedad y crimen. Pero, sobre todo, la verdad más incómoda es la noción de una posible disolución del poder patriarcal, en la medida en que el cuerpo masculino, se desconecte de la racionalidad y de la lógica discursiva de la cultura normativa, y sucumba con gusto ante la penetración anal. (párr. 3)

La obra de Guerrero se ha insertado, en esta genealogía de cuerpos insumisos, de manera particular con respecto de los artistas comentados anteriormente, puesto que -partiendo de su propia experiencia de la exclusión y rechazo en distintos espacios sociales-,

\section{Figura 8}

Roberto Guerrero, "El futbolista delicado de la selección”, Serie: Men's Magazines, fotografía digital, (2005)

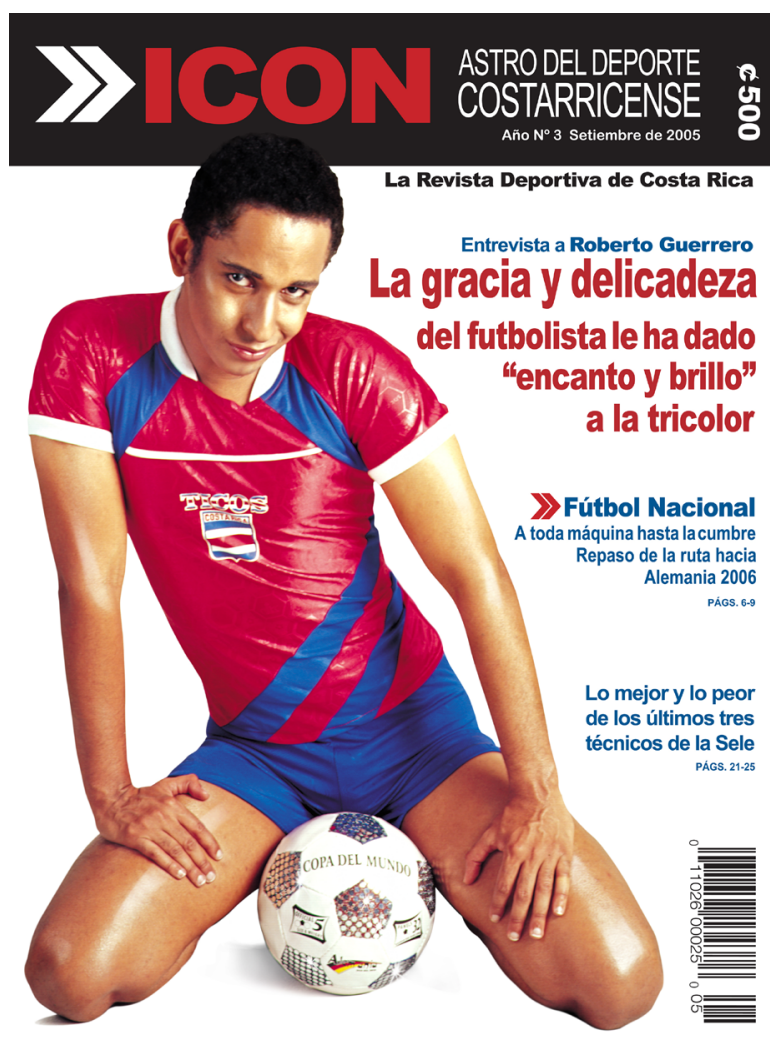

Fuente: Roberto Guerrero 


\section{Artículos}

durante su niñez y adolescencia, reconoce su diferencia y la convierte en catalizador para la transgresión de lo normativo. A tal punto que, en la actualidad, trabaja, por medio del arte, sobre el señalamiento del posible fallo de lo que se entiende como identidad heterosexual; en referencia a la idea de Judith Butler (2002) de que, en el plano discursivo, " [...] la heterosexualidad normativa modela un perfil que vacila entre la materialidad y lo imaginario [siendo entonces] la vacilación lo que determina su esencia" (p.77). Lo interesante de este último proceso de creación artística es que, discursivamente, se desplaza desde lo exclusivamente autorreferencial hacia el trabajo, con las experiencias de otros, en el espacio colectivo.

Para cerrar esta genealogía de insumisión, como proceso de creación artística emergente, se encuentra el trabajo de Andrés Rangel (n. 1991), quien pertenece a una generación muy distinta a todas las anteriores. En su proceder, reconoce un interés deliberado por la transgresión de las normas, característica que lo vincula a los discursos de Roberto Guerrero; no obstante, a diferencia de éste, Rangel ya ha naturalizado a tal punto su diferencia y se ha asimilado en una generación muy joven, que sabe que, a pesar de las manifestaciones polimorfas y perennes de la homofobia, no tiene que esconderse ni sentirse excluida o tan violentada por la sociedad patriarcal, ni tampoco le resulta necesario problematizar a lo heteronormativo como una forma de resistencia simbólica. Rangel pertenece a una generación que parece ser, cada vez, más porosa en cuanto a

\section{Figura 9}

Andrés Rangel, Sin título, Serie: Collage N., fotografía digital, (2013)

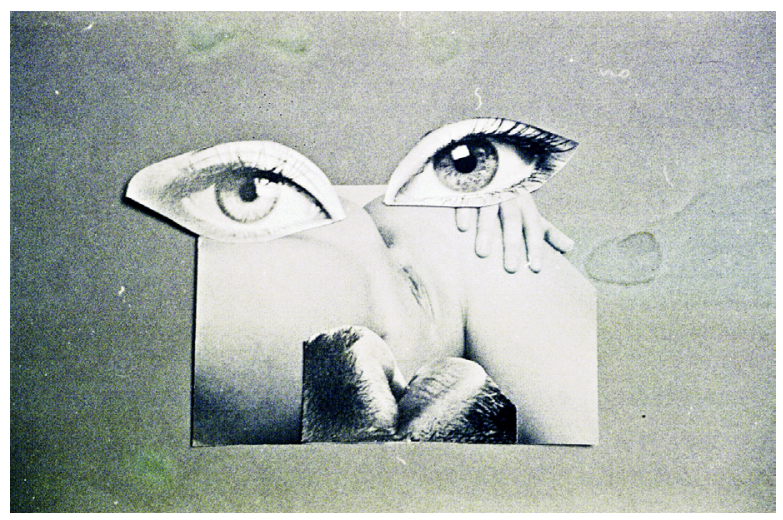

Fuente: Andrés Rangel

la economía de sus placeres y del manejo de sus cuerpos, por lo que la sexualidad -dentro o fuera de la norma- no es un problema para el artista, sino un mecanismo que le permite explorar el cuerpo eróticamente y, a su vez, convertir esa exploración en objeto de su creación artística. Por ejemplo, en la justificación de un proceso de investigación artística, Rangel (2016) explica:

Espero sonar gráfico cuando digo que un pene tuvo que eyacular dentro de una vagina para que vos y yo existamos (en la mayoría de los casos, dejando de lado la fecundación in vitro y la inseminación artificial), y que no todos se penetran con fines reproductivos, y que no siempre se penetran lugares «penetrables» y que no siempre la penetración es efectuada por un miembro con piel humana y que, de todos modos, no siempre se acude a la penetración.

El sexo es de interés público, no es secreto. Me rehúso a sentirme incómodo, 


\section{Figura 10}

Andrés Rangel, Sin título, Serie: Collage N., fotografía digital, (2013)

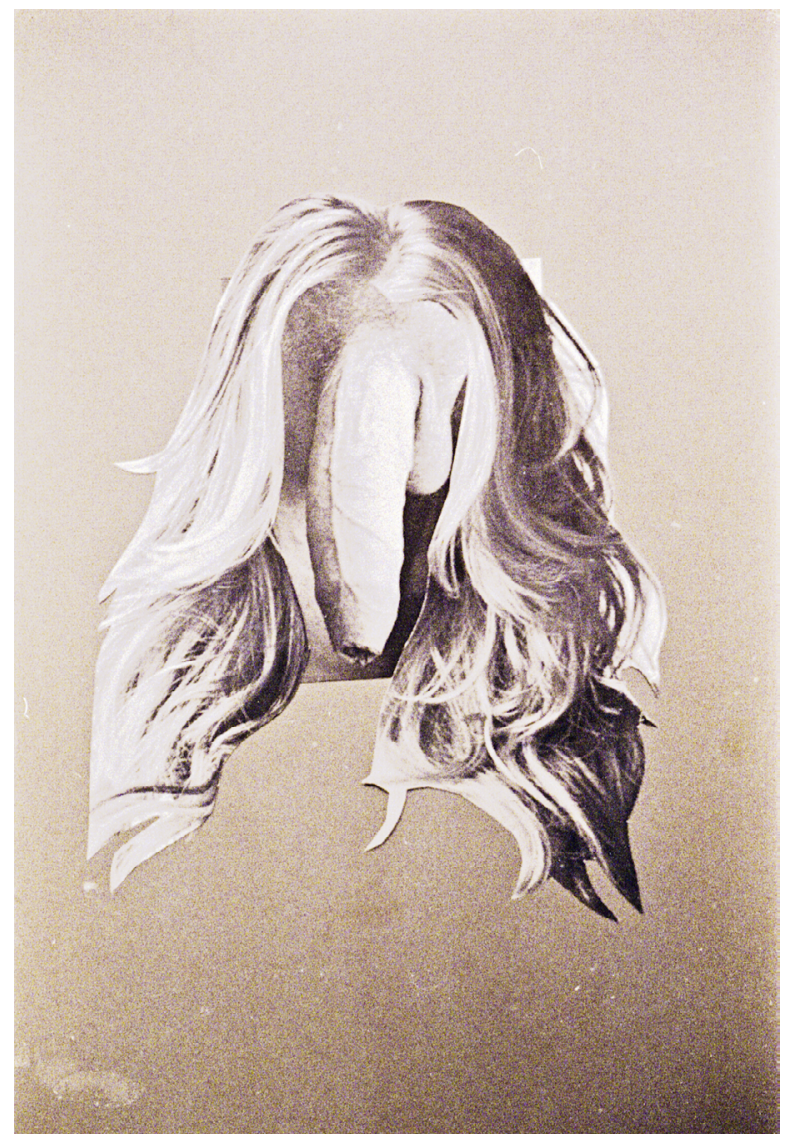

Fuente: Andrés Rangel

avergonzado, descarado o culpable por hablar sobre sexo en voz alta, porque considero que debe ser una conversación más, ni buena ni mala, simplemente libre e indigna de juicio alguno ya que de ahí venimos y hacia allá vamos. (p.1)

Esta forma de concebir la subjetividad propia, ligada a la vivencia de lo carnal sin

\section{Figura 11}

Andrés Rangel, Sin título, Serie: Collage N., fotografía digital, (2013)

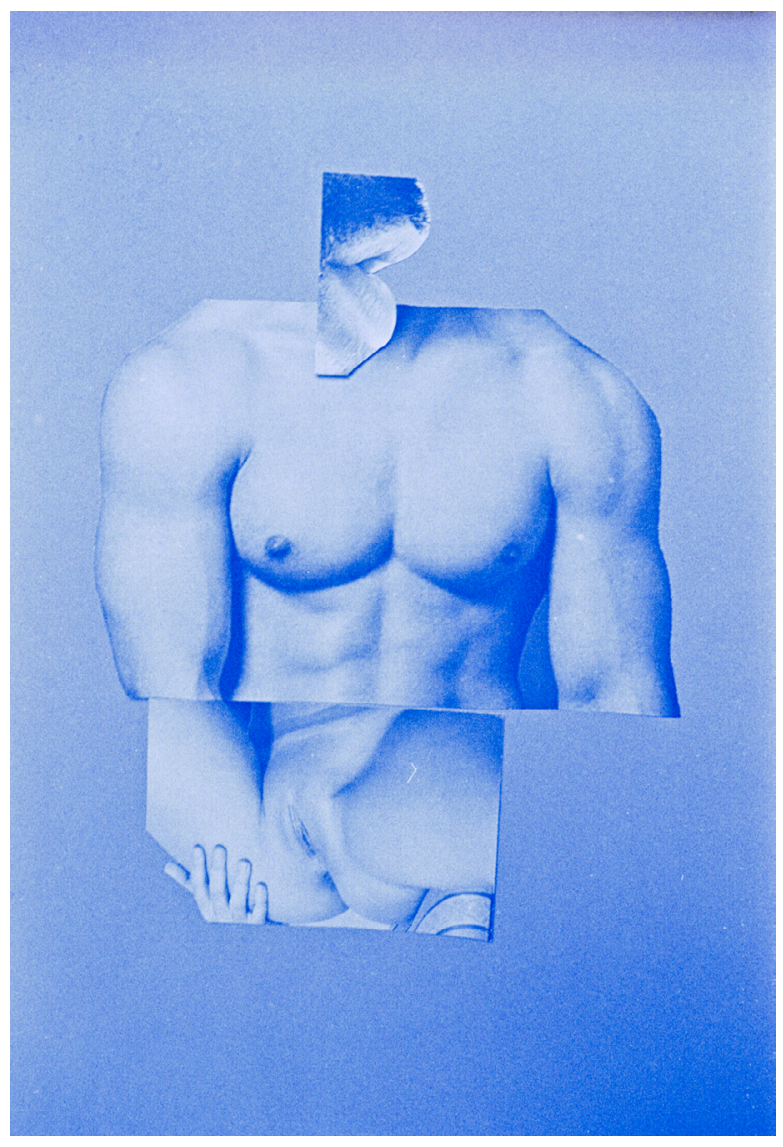

Fuente: Andrés Rangel

ataduras ni condicionamientos, resulta ser la forma mas contundente de revolución o de disidencia desde lo corporal, si se ve desde la óptica de sujetos y de una sociedad que, en términos generales, nunca han sabido cómo lidiar con sus cuerpos. Resulta además relevante el hecho de que la fotografía, para un artista emergente como Andrés Rangel, constituye también un campo de 


\section{Artículos}

experimentación, debido a que lo fotográfico se deshace de su especificidad mediática y dialoga con imágenes generadas por otros dispositivos, mediante lenguajes de los nuevos medios digitales. En ese sentido, lo fotográfico se convierte en un mero soporte de discursos, el cual se diluye en una visualidad más amplia, global y tan porosa como la sexualidad misma, la cual siempre se ha caracterizado por resistirse a que le impongan límites.

\section{Conclusiones}

El espacio de tiempo comprendido entre finales de la década de los ochenta y el año 2016, ha permitido comentar y comparar aspectos de la obra fotográfica de Giorgio Timms, Jaime David Tischler, Sussy Vargas, Roberto Guerrero y Andrés Rangel, y así determinar su participación activa y diferente, en cada caso, en la manifestación de la disidencia sexual en el contexto costarricense, desde el espacio de la creación artística.

A partir de las representaciones fotográficas, se pudo trazar una línea que enlazó, en un primer momento (1989) la enunciación de una mirada homoerótica -en la fotografía de Giorgio Timms- que convirtió al cuerpo masculino en objeto de contemplación "a cierta distancia pudorosa”, pero que implicó, visto desde hoy, la primera irrupción de la disidencia sexual en Costa Rica. Después, con un segundo momento (alrededor de 1997) en el que Jaime Tischler representó el deseo y el amor homosexual por medio del retrato, el autorretrato y registro del encuentro sexual de cuerpos masculinos. Luego, con un tercer momento (a partir del año 2000), en que Sussy Vargas trabajó su identidad lésbica, con las dificultades que implicaba, en una sociedad profundamente patriarcal, hablar del deseo desde y en el cuerpo femenino, en primera instancia, y además, no normativo y disidente, en segunda instancia.

Posteriormente, con un cuarto momento (2004), en el que Roberto Guerrero utilizó la fotografía como un recurso discursivo para emplazar a una subjetividad gay definida desde lo femenino en lo masculino e intentar transgredir las lógicas de pensamiento heteronormativas. Finalmente, un quinto momento (2013-2016), en el cual el artista emergente Andrés Rangel, en este tiempo, concibe tanto su cuerpo y sexualidad como los de otros, como objetos de experimentación constante, permitiendo volver a la noción de "liberación" de Guattari, la cual, según este autor, se gestiona mediante la acción de un "cuerpo revolucionario" (párr. 8), que se impone a un sistema-mundo patriarcal, heteronormativo y colonizado. Quedaría por analizar, a futuro y con mayor profundidad, las posibles relaciones entre esos momentos de manifestación de la disidencia sexual, y las condiciones etarias y visiones de mundo y un espectro más amplio de situaciones socioculturales, dentro del ámbito costarricense, en medio de las cuales se hayan construido las subjetividades de cada uno de los artistas.

También, a partir de las prácticas fotográficas, se pudo observar cómo esta creción -de 


\section{Artículos}

forma independiente a las inquietudes discursivas que le den origen-, no es un acto unívocamente conceptual; por el contrario, dicho acto dialoga, de manera inevitable, con la forma y la técnica de las fotografías y cómo, en el caso de la revisión de una genealogía de la disidencia sexual en Costa Rica, en ciertos momentos, esas dimensiones de la fotografía se imbricaron con la recepción de las obras de Giorgio Timms y Jaime Tischler, permitiendo formular la hipótesis -que necesita ser probada- de que hay una conexión entre las valoraciones de las imágenes en notas periodísticas y la inteligibilidad social de las identidades y cuerpos disidentes.

Finalmente, se reconoció, por un lado, la capacidad de la fotografía de visibilizar al cuerpo negado e insumiso $y$, al mismo tiempo, de reinscribirlo como un espacio discursivo que importa en el campo de la inteligibilidad social - parafraseando a Butler (2002, p.58); de constituir el vehículo para ejercer la imaginación artística como una forma de desobediencia y de operar como un recurso de interpelación ideológica para repensar y perfilar la identidad propia y la de otros, como una posibilidad hacia la descolonización. Por otro lado, se reconoció la vigencia de las representaciones del cuerpo como un arma o herramienta para la batalla por el reconocimiento social de lo negado $y$ excluido, en la medida se señalen o muestre la operatividad de los discursos heteronormativos y hegemónicos y las marcas que dejan en los sujetos.

\section{Referencias}

Alvarado, I. y Hernández, E. (2004). Últimas tendencias (1980-2003). La mirada del tiempo. Historia de la Fotografía en Costa Rica 1848-2003. Costa Rica: Fundación Museos del Banco Central.

Ardón, J. ( 20 de febrero de 2000). Mirar a Jaime. La Nación. Suplemento Áncora. Recuperado de http://wvw.nacion.com/ ancora/2000/febrero/20/ancora9.html

Butler, J. (2002). Los cuerpos que importan: sobre los límites materiales y discursivos del sexo. En: Estudios avanzados de performance. México: Fondo de Cultura Económica.

Dobles, A. (30 de enero de 2005). Domingo Siete: Jaime Tischler. En la piscina honda. La Nación. Suplemento Áncora. Recuperado de http://wvw.nacion.com/ancora/2005/enero/30/ancora4.html

Foucault, M. (2008). Vigilar y Castigar. Argentina: Siglo XXI Editores.

Guattari, F. (2003). Para acabar con la masacre del cuerpo. Fractal, 69: 59-68. Recuperado de http://www.mxfractal.org/ RevistaFractal69FelixGuattari.htm

Guerrero, R. (2015). Repensando la vergüen$z a$. Manuscrito presentado para su publicación por Museo de Arte y Diseño Contemporáneo.

Mandel Katz, C. (s.f.). Cuerpos disidentes en América Latina. Ponencia dictada en Universidad de Costa Rica. Recuperado de Recuperado de http://ciem.ucr.ac.cr/alas/ 


\section{Artículos}

docs/GT-30/Cuerpos\%20disidentes\%20 en\%20am\%C3\%A9rica\%20latina.docx

Pérez, D. (Ed.). (2004). La certeza vulnerable: cuerpo y fotografía en el siglo XXI. Barcelona: Editorial Gustavo Gili.

Rangel, A. (2016). Por No: Problematización de la incomunicación sexual. (Tesis de Licenciatura). Universidad Veritas, Costa Rica.
Reseña informativa sobre Poemas Cotidianos de Sussy Vargas. (13 de julio de 2014). La Nación. Suplemento Áncora.

Rodríguez, C. (2006). Giorgio Timms. Pionero del desnudo. ArtStudio Magazine. Recuperado de http://www.artstudiomagazine.com/personajes/giorgio-timms.html

Rojas, J. (30 de marzo de 1997). Fotógrafo o demiurgo. La Nación. Suplemento Áncora. 